\title{
BMJ Open Associations of alcoholic beverage preference with cardiometabolic and lifestyle factors: the NQplus study
}

\author{
Diewertje Sluik, Elske M Brouwer-Brolsma, Jeanne H M de Vries, Anouk Geelen, \\ Edith J M Feskens
}

To cite: Sluik D, BrouwerBrolsma EM, de Vries JHM, et al. Associations of alcoholic beverage preference with cardiometabolic and lifestyle factors: the NQplus study. BMJ Open 2016;6: e010437. doi:10.1136/ bmjopen-2015-010437

- Prepublication history and additional material is available. To view please visit the journal (http://dx.doi.org/ 10.1136/bmjopen-2015010437).

Received 3 November 2015 Revised 2 March 2016 Accepted 14 April 2016

\section{CrossMark}

Division of Human Nutrition, Wageningen University, Wageningen, The Netherlands

Correspondence to Dr Diewertje Sluik; Diewertje.Sluik@wur.nl

\section{ABSTRACT}

Objectives: The preference for a specific alcoholic beverage may be related to an individual's overall lifestyle and health. The objective was to investigate associations between alcoholic beverage preference and several cardiometabolic and lifestyle factors, including adiposity, cholesterol, glycated haemoglobin $\left(\mathrm{HbA}_{1 \mathrm{c}}\right)$, liver enzymes and dietary patterns.

Design: Cross-sectional study.

Setting: The Dutch Longitudinal Nutrition Questionnaires plus (NQplus) Study.

Participants: 1653 men and women aged 20-77 years.

Methods: Diet, including alcohol, was assessed by Food Frequency Questionnaire. Based on the average number of reported glasses of alcoholic beverage, a person was classified as having a preference for beer, wine, spirit/no specific preference, or as a nonconsumer. Mixed linear models were used to calculate crude and adjusted means of cardiometabolic and lifestyle factors across alcoholic beverage preference categories.

Primary outcome measures: Anthropometric measures, blood pressure, lipids, $\mathrm{HbA}_{1 \mathrm{c}}$, albumin, creatinine, uric acid, liver enzymes and dietary patterns.

Results: In the study population, $43 \%$ had a wine preference, $13 \%$ a beer preference, $29 \%$ had a spirit or no specific preference, and $15 \%$ did not consume alcohol. Men who preferred wine had lowest measures of adiposity; the preference for alcoholic beverages was not associated with adiposity measures in women. Wine consumers had higher high density lipoproteincholesterol, lower $\mathrm{HbA}_{1 \mathrm{c}}$ and were more likely to follow the 'Salad' pattern. Beer consumers had highest levels of triglycerides and liver enzymes, and had higher scores for the 'Meat' and 'Bread' pattern.

Conclusions: Few differences in dietary patterns across alcoholic beverage preference categories were observed. Those differences in cardiometabolic parameters that were observed according to alcoholic beverage preference, suggested that wine consumers have a better health status than beer consumers.

\section{INTRODUCTION}

Research indicates that cardiovascular disease (CVD) incidence is lower in wine-drinking countries than other countries, suggesting

\section{Strengths and limitations of this study}

- We studied the association between alcoholic beverage preference and a wide range of cardiometabolic and lifestyle factors.

- To ensure appropriate adjustment and to minimise bias, confounding factors were selected using directed acyclic graphs, and missing values for any of the covariates were addressed with multiple imputation.

- Nevertheless, residual confounding due to imperfectly measured variables may have occurred.

- Owing to the cross-sectional design of the study, no causal relationship between the choice of alcoholic beverage and lifestyle habits and health could be confirmed.

that moderate wine consumption may be more beneficial than the consumption of other alcoholic beverages, such as beer and spirits. ${ }^{1}$ This hypothesis is further strengthened by studies reporting differential associations between alcoholic beverages and CVD risk, mostly in favour of wine consumption. ${ }^{2-4}$ However, it remains unclear whether these associations can be directly attributed to wine consumption. People who prefer wine may differ from people preferring other alcoholic beverages with regard to lifestyle factors, including their diet.

A number of studies have investigated the associated dietary habits according to the consumption of wine, beer or spirits. ${ }^{5-8}$ In Western countries comprising North-Western Europe and the USA, it was found that persons with a wine preference had in general healthier dietary habits than persons with other preferences. In contrast, this association was less clear in Mediterranean countries. ${ }^{9}$ This discrepancy may be due to the fact that in Western countries, wine consumers are usually older, female, and have a higher socioeconomic status, whereas in Mediterranean countries, wine is economically affordable for 
all social classes. Hence, it may be that the choice of alcoholic beverage is strongly driven by the socioeconomic status.

Therefore, the aim of this cross-sectional study was to investigate the association between alcoholic beverage preference and the following cardiometabolic and lifestyle factors: adiposity measures, blood pressure, levels of various biomarkers (including cholesterol, glycated haemoglobin $\left(\mathrm{HbA}_{1 \mathrm{c}}\right)$, liver enzymes), dietary patterns and potential confounding factors.

\section{MATERIALS AND METHODS}

\section{Study design and population}

The Nutrition Questionnaires plus (NQplus) study is an ongoing longitudinal study on diet and health within the Wageningen and surrounding cities, all located in the central part of the Netherlands. Adult men and women aged 20-77 years were recruited between May 2011 and February 2013 by sending electronic invitations for joining the 'EetMeetWeet' research panel to randomly selected inhabitants from the municipality registers of Ede, Wageningen, Renkum ( $\mathrm{n}=30000)$ and Arnhem ( $\mathrm{n}=15000)$. In addition, all households in Veenendaal $(n=25000)$ received an invitation letter. If interested, participants could register online. Inclusion criteria were to be able to speak and write Dutch, and competent to make their own decisions. A total of 7437 men and women registered for the 'EetMeetWeet' research panel, and a subgroup of $n=2048$ men and women agreed to participate in the NQplus study. The NQplus study was approved by the medical ethical committee of Wageningen University, and was conducted according to the guidelines laid down in the declaration of Helsinki. All participants gave written informed consent.

\section{Dietary assessment}

Of the 2048 participants, a total of 1653 filled out a semiquantitative Food Frequency Questionnaire (FFQ) at baseline. This 180-item FFQ was used to assess usual dietary intake and was previously validated for energy intake, macronutrients, dietary fibre and selected vitamins. ${ }^{10}{ }^{11}$ Answer categories for frequency questions ranged between 'never per month' to '6-7 days/week', and portion sizes were estimated using natural portions (bread shapes) and commonly used household measures (eg, spoon and cup). Average daily nutrient intakes were calculated by multiplying frequency of consumption by portion size and nutrient content per gram using the 2011 Dutch food composition table. ${ }^{12}$ The FFQ was administered online using the open-source survey tool Limesurvey. The food items were grouped into 32 food groups; subgroups of dairy, cheese, cereals and fats were constructed based on the fat-content and fibre-content (see online supplementary table 1).

\section{Definition alcoholic beverage preference}

A person was classified as having a preference for beer, wine or spirits when the average number of reported glasses of the respective drink in the FFQ comprised $70 \%$ or more of the total number of glasses of alcoholic beverage. ${ }^{13}$ It was assumed that a glass of beer contained $250 \mathrm{~mL}$, a glass of wine $100 \mathrm{~mL}$ and a glass of spirits $35 \mathrm{~mL}$ of the beverage. ${ }^{14}$ Spirits comprised all liquors and distilled beverages such as gin, whiskey, rum and liqueur. When the average number of glasses of beer, wine or spirits did not add up to $70 \%$ of the total number of glasses of alcohol, a person was classified as having 'no preference'. Owing to the low frequency, the categories of 'spirit preference' and 'no preference' were combined into one category. As most differences in diet and lifestyle have been observed in those who preferred wine or beer and among nonconsumers, it was not expected that by combining these categories any distinct differences would be overlooked.

\section{Dietary pattern analysis}

Major dietary patterns were identified with a principal component analysis (PCA) on 32 energy-adjusted food groups, excluding alcoholic beverages. Non-normally distributed food group intakes were log-transformed before analyses, and intakes were adjusted for energy by the residual method. ${ }^{15}$ Based on the Eigenvalues, visual inspection of the scree plot and interpretability of the factors, six factors were extracted and rotated using the Varimax orthogonal rotation. These six factors explained $36 \%$ of the total variance. Food groups with factor loadings $<-0.20$ and $>0.20$ were included in the patterns; these groups are shown in table 1 . The first pattern 'Meat' was characterised by a high intake of meat, potatoes, cooking fat and a low intake of wholegrain pasta and rice, vegetarian products, legumes and nuts. The second factor 'Snacks' was characterised by a high intake of snacks, sauces and condiments, non-alcoholic beverages, refined pasta and rice, and a low intake of fruit, coffee and tea. The third factor 'Salads' included a high intake of vegetables, oils and dressing, fish, fruit, soup, and eggs, and a low intake of sweets, snacks, and cake and cookies. The factor 'Bread' included a high intake of wholegrain bread, margarine, processed meat, and potatoes, and a low intake of nuts, cooking fat, eggs and cereals. The factor 'Potatoes and sweets' included a high intake of potatoes, sweets, cake, cookies, cooking fat, semifat and full-fat dairy, white bread, coffee and tea. Finally, the sixth factor 'Low-fat dairy and cereals' was characterised by a high intake of cereals, low-fat cheese and dairy, wholegrain pasta and rice, and a low intake of sweets and cooking fat.

\section{Anthropometric and blood pressure measurements}

At baseline, trained research assistants performed physical measurements following a standardised protocol; however, reproducibility of these measurements was not assessed. During anthropometric measurements, participants were requested to take off their shoes and heavy clothing. Weight was measured to the nearest $100 \mathrm{~g}$, using a digital scale or a regular scale. Standing height was measured once, with a portable stand-alone stadiometer, to the nearest centimetre by standard stretch 
Table 1 Rotated factor pattern scores of 32 energy-adjusted food groups using principal component analysis yielding six factors. Scores with factor loadings $<-0.20$ and $>0.20$ are shown

\begin{tabular}{|c|c|c|c|c|c|c|}
\hline & $\begin{array}{l}\text { Factor } 1 \\
\text { 'Meat' }\end{array}$ & $\begin{array}{l}\text { Factor } 2 \\
\text { 'Snacks } \\
\text { and drinks' }\end{array}$ & $\begin{array}{l}\text { Factor } 3 \\
\text { 'Salads' }\end{array}$ & $\begin{array}{l}\text { Factor } 4 \\
\text { 'Bread' } \\
\end{array}$ & $\begin{array}{l}\text { Factor } 5 \\
\text { 'Potatoes } \\
\text { and sweets' }\end{array}$ & $\begin{array}{l}\text { Factor } 6 \\
\text { 'Low-fat dairy } \\
\text { and cereals' }\end{array}$ \\
\hline Eigenvalue & 3.28 & 1.96 & 1.85 & 1.54 & 1.49 & 1.29 \\
\hline Potatoes & 0.204 & & & 0.253 & 0.591 & \\
\hline $\begin{array}{l}\text { Wholegrain pasta and } \\
\text { rice }\end{array}$ & -0.394 & & 0.241 & & & 0.367 \\
\hline Nuts & -0.340 & & & -0.245 & & \\
\hline Legumes & -0.230 & & 0.356 & & & \\
\hline Vegetarian products & -0.586 & & 0.237 & & & \\
\hline Sweets & -0.212 & & -0.267 & & 0.435 & \\
\hline Oils and dressing & -0.228 & & 0.589 & & & \\
\hline Cooking fat & 0.214 & & & -0.257 & 0.489 & -0.245 \\
\hline Red meat & 0.772 & & & & & \\
\hline Processed meat & 0.696 & & & 0.202 & & \\
\hline Poultry & 0.642 & & & & & \\
\hline Plain pasta and rice & & 0.332 & & & & -0.230 \\
\hline Fruit & & -0.415 & 0.220 & & & 0.261 \\
\hline Coffee and tea & & -0.270 & & & 0.241 & \\
\hline $\begin{array}{l}\text { Non-alcoholic } \\
\text { beverages }\end{array}$ & & 0.504 & & & & \\
\hline Juice & & 0.380 & & & & \\
\hline Snacks & & 0.639 & -0.204 & & & \\
\hline Sauces and condiments & & 0.635 & & & & \\
\hline Vegetables & & & 0.683 & & & \\
\hline Soup & & & 0.359 & & & \\
\hline Cake and cookies & & & -0.316 & & 0.432 & \\
\hline Eggs & & & 0.333 & -0.207 & & \\
\hline Fish & & & 0.342 & & & \\
\hline Cereals & & & & -0.305 & & 0.455 \\
\hline Wholegrain bread & & & & 0.791 & & \\
\hline Margarine & & & & 0.772 & & \\
\hline White bread & & & & & 0.376 & -0.235 \\
\hline Full-fat dairy & & & & & 0.400 & -0.318 \\
\hline Semifat dairy & & & & & 0.383 & 0.207 \\
\hline Low-fat cheese & & & & & & 0.424 \\
\hline Full-fat cheese & & & & & & -0.475 \\
\hline Low-fat dairy & & & & & & 0.556 \\
\hline
\end{tabular}

stature method. Body mass index (BMI) was calculated as weight divided by squared height $\left(\mathrm{kg} / \mathrm{m}^{2}\right)$. Waist circumference was measured twice with a non-flexible body tape measure. Waist-height-ratio was studied as an indicator for abdominal obesity since it has been shown to carry more information than other anthropometric indices in predicting cardiometabolic risk. ${ }^{16}$ Total body fat percentage was assessed with dual-energy X-ray absorptiometry. Systolic and diastolic blood pressure was measured six times with a sphygmomanometer after 20 min of rest with the participant in a supine position. The first measurement was not used; the five remaining measurements were averaged.

\section{Biomarker assessment}

After a $10 \mathrm{~h}$ overnight fast, $24 \mathrm{~mL}$ of blood was drawn from an antecubital vein using venepuncture. Blood was immediately centrifuged and plasma was stored at $-80^{\circ} \mathrm{C}$ until further analyses. Total cholesterol, high density lipoprotein (HDL) cholesterol, triglycerides, creatinine and uric acid were determined by serum using enzymatic methods using a Dimension Vista 1500 automated analyser or Roche Modular P800 chemistry analyser. Low density lipoprotein (LDL) cholesterol was calculated with the Friedewald equation. ${ }^{17}$ Catalytic activity concentration of alanine aminotransferase (ALT), aspartate aminotransferase (AST) and $\gamma$ glutamyltransferase (GGT) were measured by international federation of clinical chemistry reference procedures at $37^{\circ} \mathrm{C}$. For albumin determinations, the bromocresol purple method was used. ${ }^{18} \mathrm{HbA}_{1 \mathrm{c}}$ was determined with high-performance liquid chromatography (HPLS) measurement technology using an ADAMSTM A1c HA-8160 analyser. 


\section{Covariate assessment}

Demographics, medical history, medication use and lifestyle factors were assessed through questionnaires. Physical activity was assessed using the Short Questionnaire to Assess Health (SQUASH) and the Activity Questionnaire for Adults and Adolescents (AQuAA). Prevalent major CVD was defined as a self-reported diagnosis of myocardial infarction or stroke. Prevalent diabetes, hypertension and hypercholesterolaemia were defined as a self-reported diagnosis or self-reported medication use.

\section{Statistical analysis}

All statistical analyses were performed with SAS 9.3 (SAS Institute, Cary, NG). Proportion of missing covariates were $<1 \%$ for age, sex, nationality, education, anthropometric measurements, blood pressure, and prevalence and medication use for diabetes, heart diseases, cancer, hypertension, and hypercholesterolemia, and $4 \%$ for blood parameters, $11 \%$ for body fat percentage, $13 \%$ for physical activity and $15 \%$ for smoking status. These missing values were imputed using the multiple imputation method, where all variables included in the statistical models were included in the procedure. ${ }^{19}$ Twenty duplicate data sets were produced and after statistical inference on the duplicate data sets, pooled estimates were calculated with PROC MIANALYZE.

Crude and adjusted means and SEs of lifestyle factors across alcoholic beverage preference categories were calculated using mixed linear models. Differences between categories were tested by a t-test for differences of least squares means.

Putative confounding factors for the association between anthropometric factors, blood parameters and diet were selected using directed acyclic graphs (DAGs). ${ }^{20}$ The DAGs revealed a minimal sufficient adjustment set of the following variables: age (years), gender, education (low: none/lower/lower vocational; medium: intermediate/intermediate vocational; and high: higher vocational/university), birth country (the Netherlands/other), employment status (yes/no), prevalent diseases (yes/no, including prevalent diabetes, heart disease, cancer), hypertension (yes/no) and hypercholesterolaemia (yes/no). Additional adjustment for smoking status (never, former, current), physical activity (minutes per week), diet (first three factors identified with PCA on 32 energy-adjusted food groups), and absolute alcohol consumption (log-transformed; gram/ day) did not change the effect estimates and the differences across preference categories. Therefore, only estimates corrected for the minimal sufficient adjustment set of covariates is shown.

Results for adiposity measures are shown separately for men and women due to sex-specific differences in measures and associations; other results did not differ according to sex. A sensitivity analysis was performed excluding persons with prevalent diabetes, cancer, CVDs, hypertension and hypercholesterolaemia $(n=610$ excluded). A p value of $<0.05$ was considered to be statistically significant.

\section{RESULTS}

\section{General characteristics}

Table 2 shows the general characteristics of the study population across categories of alcoholic beverage preference. In general, absolute alcohol consumption was moderate in all preference categories. Among the 1653 participants, $43 \%$ had a preference for wine, $13 \%$ a preference for beer, $4 \%$ had a preference for spirits, $25 \%$ had no specific preference and $15 \%$ reported to not consuming alcohol. Persons with a wine preference were more likely to be older and higher educated. Beer consumers had the highest crude absolute alcohol intake, were more physically active and most likely to be male and current smokers. Those with a preference for spirits or no specific preference were most likely to have hypertension. Non-consumers were more likely to be young, female, and to never have smoked.

\section{Adiposity measures}

After adjustment, BMI, waist circumference, waist-height-ratio and body fact percentage were lower in men with a wine preference than those who preferred other alcoholic beverages (table 3 ). In women, no statistically significant associations were observed after adjustment.

\section{Blood pressure and biomarkers}

Associations between alcoholic beverage preference and blood pressure, cholesterol levels, triglycerides, $\mathrm{HbA}_{1 \mathrm{c}}$, albumin, liver enzymes (ALT, AST, GGT), creatinine and uric acid are shown in table 4. After adjustments, persons with a beer preference displayed highest systolic blood pressure, triglyceride, ALT and GGT levels. Furthermore, persons with a wine preference had the highest HDL-cholesterol and the lowest $\mathrm{HbA}_{1 \mathrm{c}}$ values. Moreover, non-consumers had the lowest total cholesterol and uric acid levels.

\section{Dietary patterns}

Compared to other preference categories, nonconsumers had lowest scores for the 'Meat' pattern and more for the 'Bread' pattern (table 5). Furthermore, non-consumers and beer consumers had lowest scores for the 'Salads' pattern. Persons with a preference for spirits or no specific preference had highest scores for the 'Potatoes and sweets' pattern. After adjustment, no associations between beverage preference and the 'Snacks' and 'Low-fat dairy and cereals' pattern were observed.

Persons without prevalent diseases had lower absolute levels of adiposity measures and biomarkers; however, differences between categories were similar. Thus, excluding persons with prevalent diseases from the analyses did not change the results. 
Table 2 General characteristics† according to alcoholic beverage preference of 1653 participants from the NQplus study

\begin{tabular}{|c|c|c|c|c|}
\hline & \multicolumn{3}{|c|}{ Alcoholic beverage preference } & \multirow[b]{2}{*}{ Non-consumer } \\
\hline & Beer & Wine & Spirit/no preference & \\
\hline $\mathrm{N}(\%)$ & $222(13)$ & $703(43)$ & $483(29)$ & $245(15)$ \\
\hline Age, years & $50.2(12.4)$ & $54.5(10.9)^{*}$ & $53.8(11.8)^{\star}$ & $47.9(12.6)^{\star \star, \star \star \star}$ \\
\hline Men, n (\%) & $194(87)$ & $456(65)^{*}$ & $339(70)^{\star, \star *}$ & $79(32)^{\star, \star \star \star}$ \\
\hline Ethanol, g/day & $11(4-22)$ & $9(4-17)^{*}$ & $8(4-19)$ & $0(0-0)^{\star, \star *, \star \star \star}$ \\
\hline \multicolumn{5}{|c|}{ Alcoholic beverage consumption, $\mathrm{mL} /$ day } \\
\hline Beer & $214(89-446)$ & $0(0-21)^{*}$ & $54(10-161)^{\star, \star \star}$ & $0(0-0)^{\star, \star \star \star}$ \\
\hline Wine & $0(0-13)$ & $80(35-145)^{\star}$ & $27(10-78)^{\star, \star \star}$ & $0(0-0)^{\star *, \star * *}$ \\
\hline Spirits & $0(0-2)$ & $0(0-1)$ & $4(1-12)^{\star, \star \star}$ & $0(0-0)^{\star \star \star}$ \\
\hline Energy, kcal/day & 2290 (642) & $1933(527)^{*}$ & $2182(620)^{\star \star}$ & $1911(630)^{\star, \star \star \star}$ \\
\hline Physical activity, min/week & $2086(1186)$ & $1787(1223)^{*}$ & 1954 (1279) & 1926 (1365) \\
\hline \multicolumn{5}{|l|}{ Smoking status, $\mathrm{n}(\%)$} \\
\hline Never & $84(44)$ & $291(49)$ & $203(50)$ & $138(67)^{\star, \star \star, \star \star \star}$ \\
\hline Former & $84(44)$ & $262(44)$ & $169(41)$ & $51(25)^{\star, \star \star, \star \star \star}$ \\
\hline Current & $24(13)$ & $44(7)$ & $38(9)$ & $16(8)$ \\
\hline Employed, n (\%) & $158(72)$ & $455(69)$ & $325(69)$ & $169(73)$ \\
\hline \multicolumn{5}{|l|}{ Education, n (\%) } \\
\hline Low & $27(12)$ & $40(6)^{\star}$ & $30(6)^{\star}$ & $23(9)$ \\
\hline Middle & $99(45)$ & $275(39)$ & $194(41)$ & $113(46)$ \\
\hline High & $96(43)$ & $384(55)^{*}$ & $255(53)$ & $108(44)^{\star \star}$ \\
\hline \multicolumn{5}{|l|}{ Prevalent diseases, n (\%) } \\
\hline Cancer & $7(3)$ & $44(6)$ & $29(6)$ & $10(4)$ \\
\hline Major CVD & 7 (3) & $22(3)$ & $12(3)$ & $6(2)$ \\
\hline Diabetes & $6(3)$ & $19(3)$ & $21(4)$ & $12(5)$ \\
\hline Hypertension & $37(17)$ & $170(24)$ & $131(27)^{\star}$ & $65(27)$ \\
\hline Hypercholesterolaemia & 39 (18) & 134 (19) & $98(20)$ & $36(15)$ \\
\hline \multicolumn{5}{|l|}{ Medication use, n (\%) } \\
\hline Hypertension & $17(8)$ & $97(14)$ & $78(16)^{\star}$ & $33(14)$ \\
\hline Hypercholesterolaemia & $18(8)$ & $70(10)$ & $98(20)$ & $17(7)$ \\
\hline Diabetes & $5(2)$ & $15(2)$ & $18(4)$ & $11(5)$ \\
\hline
\end{tabular}

\section{DISCUSSION}

In this cross-sectional analysis of 1653 persons enrolled in the NQplus study, alcoholic beverage preference was associated with various measures of adiposity, dietary patterns and cardiometabolic risk factors. These associations remained after full adjustment for confounders. More specifically, compared to the other preference categories, wine consumers had higher HDL-cholesterol a lower $\mathrm{HbA}_{1 \mathrm{c}}$ and were more likely to follow the 'Salad' pattern. Moreover, men who preferred wine had lower levels of general and abdominal adiposity. Beer consumers had highest levels of triglycerides and liver enzymes, and had higher scores for the 'Meat' and 'Bread' dietary patterns.

In a previous study, we investigated associations between alcoholic beverage preference and diet within a representative subsample of the Dutch population by using data of the Dutch National Food Consumption Survey 20072010. ${ }^{13}$ Here, we found that participants with a beer preference displayed less healthy dietary habits compared to those with a wine preference. In addition, participants with a beer preference had a higher absolute intake of meat, soft drinks, margarine and snacks. These differences were largely explained by other sociodemographic and lifestyle factors. In the NQplus population, we only detected minor differences in dietary pattern according to alcoholic beverage preference. Compared to the Dutch National Food Consumption Survey which was conducted among a population representing the general Dutch population, NQplus participants were older, higher educated, had a lower absolute alcohol intake and were less likely to be a current smoker. Moreover, a much larger proportion of persons had preference for wine. Thus, the current findings underline our hypothesis that sociodemographic factors, including education and employment, may be important determinants of alcoholic beverage preference. Although we were able to correct for education and employment, we could not take into account income and occupation, which are also elements of socioeconomic status.

Although we did not observe distinct differences in dietary patterns according to alcoholic beverage 
Table 3 Crude and adjusted measures of anthropometry according to alcoholic beverage preference of 1653 men and women from the NQplus study

\begin{tabular}{|c|c|c|c|c|}
\hline & \multicolumn{3}{|c|}{ Alcoholic beverage preference } & \multirow[b]{2}{*}{ Non-consumer } \\
\hline & Beer & Wine & Spirit/no preference & \\
\hline \multicolumn{5}{|l|}{ Men } \\
\hline$\%$ & 23 & 29 & 39 & 9 \\
\hline \multicolumn{5}{|l|}{ BMI, $\mathrm{kg} / \mathrm{m}^{2}$} \\
\hline Crude & $26.3(0.3)$ & $26.1(0.2)^{\star}$ & $26.9(0.2)^{\star, \star \star}$ & $26.5(0.4)^{\star \star, \star \star \star}$ \\
\hline Adjusted & $26.7(0.3)$ & $25.9(0.2)^{*}$ & $26.8(0.2)^{\star \star}$ & $26.5(0.4)$ \\
\hline \multicolumn{5}{|l|}{ Waist, $\mathrm{cm}$} \\
\hline Crude & $96.3(0.8)$ & $96.3(0.7)$ & $98.3(0.6)^{\star, \star \star \star}$ & $95.7(1.2)^{\star \star \star}$ \\
\hline Adjusted & $97.8(0.7)$ & $95.3(0.7)^{*}$ & $98.0(0.5)^{\star *}$ & $96.1(1.1)$ \\
\hline \multicolumn{5}{|c|}{ Waist-height-ratio } \\
\hline Crude & $0.53(0.004)$ & $0.54(0.004)^{\star}$ & $0.54(0.003)^{\star, \star \star}$ & $0.53(0.01)^{\star *, \star \star *}$ \\
\hline Adjusted & $0.54(0.004)$ & $0.53(0.004)^{*}$ & $0.54(0.003)^{\star \star}$ & $0.53(0.01)$ \\
\hline \multicolumn{5}{|l|}{ Fat, \% } \\
\hline Crude & $24.9(0.5)$ & $24.2(0.4)^{\star}$ & $25.3(0.4)^{\star, \star \star}$ & $24.4(0.8)^{\star, \star \star \star}$ \\
\hline Adjusted & $25.5(0.5)$ & $23.9(0.4)^{\star}$ & $25.2(0.4)^{\star \star}$ & $24.5(0.7)$ \\
\hline \multicolumn{5}{|l|}{ Women } \\
\hline$\%$ & 4 & 58 & 18 & 21 \\
\hline \multicolumn{5}{|l|}{$\mathrm{BMI}, \mathrm{kg} / \mathrm{m}^{2}$} \\
\hline Crude & $25.6(0.8)$ & $25.2(0.2)^{\star}$ & $25.0(0.4)^{\star, \star \star \star}$ & $25.8(0.3)^{\star \star, \star \star \star}$ \\
\hline Adjusted & $25.7(0.8)$ & $25.2(0.2)$ & $25.1(0.4)$ & $25.7(0.4)$ \\
\hline \multicolumn{5}{|l|}{ Waist, $\mathrm{cm}$} \\
\hline Crude & $85.8(2.2)$ & $85.9(0.5)$ & $84.8(1.0)^{\star, \star \star}$ & $85.8(0.9)^{\star \star \star}$ \\
\hline Adjusted & $86.4(2.1)$ & $85.6(0.5)$ & $85.4(0.9)$ & $86.0(0.9)$ \\
\hline \multicolumn{5}{|c|}{ Waist-height-ratio } \\
\hline Crude & $0.51(0.01)$ & $0.51(0.003)^{*}$ & $0.50(0.01)^{\star, \star \star}$ & $0.51(0.01)^{* \star, \star \star \star}$ \\
\hline Adjusted & $0.51(0.01)$ & $0.51(0.003)$ & $0.51(0.01)$ & $0.51(0.01)$ \\
\hline \multicolumn{5}{|l|}{ Fat, \% } \\
\hline Crude & $34.0(1.5)$ & $34.7(0.4)^{\star}$ & $34.4(0.7)^{\star, \star \star}$ & $34.9(0.6)^{\star, \star \star \star}$ \\
\hline Adjusted & $34.1(1.5)$ & $34.7(0.4)$ & $34.6(0.7)$ & $34.8(0.6)$ \\
\hline
\end{tabular}

preference, some differences in cardiometabolic parameters between particularly beer and wine consumers were observed. Furthermore, it should be noted that due to the many comparisons that were made, these may also have been due to chance. Many studies have investigated the associations between alcohol consumption and cardiometabolic factors; however, not many have taken into account the type of beverage.

First, we observed that wine consumers had the highest HDL-cholesterol and beer consumers tended to have higher blood pressure levels. Chiva-Blanch et $a l^{21}$ have conducted a systematic review of clinical studies and meta-analyses from 2000 to 2012 on the relation between moderate alcohol consumption and CVD. The authors concluded a protective effect of beer, wine and spirits on insulin sensitivity, HDL-cholesterol and inflammation. However, an antihypertensive effect was not clear for any alcoholic beverage. ${ }^{21}$

Men-but not women-with a beer preference had highest levels of general and abdominal adiposity. Already several other studies investigated the association of beer consumption with abdominal and general obesity, a phenomenon also referred to as 'beer belly' ${ }^{22}{ }^{23}$ A systematic review of these studies, including 35 cross-sectional and prospective investigations, observed positive or null associations between beer intake and obesity in men; results for women were inconsistent. ${ }^{24}$ Therefore, it can be concluded that findings with regard to the impact of beer consumption on adiposity remains inconclusive.

Moreover, persons who preferred beer also had the highest triglyceride levels. An elevated waist circumference along with an elevated plasma triglyceride concentration, the so-called 'hypertriglyceridemic waist', has been shown to be a strong marker for cardiovascular risk. ${ }^{25}$ Thus, the hypertriglyceridemic waist might be more prevalent among men who prefer beer; as a result, their cardiovascular risk may also be increased. However, Chiva-Blanch $e t a l^{21}$ concluded there was no clear effect of beer, wine or spirits on triglyceride levels.

Persons with a beer preference also had the highest levels of liver enzymes, which were largely explained by 
Table 4 Crude and adjusted levels of cardiometabolic parameters according to alcoholic beverage preference of 1653 participants from the NQplus study

\begin{tabular}{|c|c|c|c|c|}
\hline & \multicolumn{3}{|c|}{ Alcoholic beverage preference } & \multirow[b]{2}{*}{ Non-consumer } \\
\hline & Beer & Wine & Spirit/no preference & \\
\hline$\%$ & 13 & 43 & 29 & 15 \\
\hline \multicolumn{5}{|c|}{ Systolic blood pressure, $\mathrm{mm} \mathrm{Hg}$} \\
\hline Crude & $130(1.0)$ & $124(0.6)^{*}$ & $129(0.7)^{\star \star}$ & $122(1.0)^{\star, \star \star, \star \star \star}$ \\
\hline Adjusted & $128(0.9)$ & $125(0.5)^{\star}$ & $127(0.6)$ & $125(0.9)^{*}$ \\
\hline \multicolumn{5}{|c|}{ Diastolic blood pressure, $\mathrm{mm} \mathrm{Hg}$} \\
\hline Crude & $76(0.7)$ & $74(0.4)^{*}$ & $76(0.5)^{\star *}$ & $73(0.6)^{*, \star \star \star}$ \\
\hline Adjusted & $75(0.7)$ & $74(0.4)$ & $75(0.4)^{*}$ & $74(0.6)$ \\
\hline \multicolumn{5}{|c|}{ Total cholesterol, $\mathrm{mmol} / \mathrm{L}$} \\
\hline Crude & $5.23(0.07)$ & $5.54(0.04)^{\star}$ & $5.29(0.05)^{\star \star}$ & $5.14(0.07)^{\star \star}$ \\
\hline Adjusted & $5.37(0.07)$ & $5.43(0.04)$ & $5.30(0.05)^{\star \star}$ & $5.26(0.07)^{\star \star}$ \\
\hline \multicolumn{5}{|c|}{ HDL-cholesterol, $\mathrm{mmol} / \mathrm{L}$} \\
\hline Crude & $1.40(0.03)$ & $1.70(0.02)^{\star}$ & $1.47(0.02)^{\star, \star \star}$ & $1.53(0.03)^{\star, \star \star}$ \\
\hline Adjusted & $1.55(0.03)$ & $1.62(0.02)^{\star}$ & $1.54(0.02)^{\star *}$ & $1.48(0.03)^{\star \star}$ \\
\hline \multicolumn{5}{|c|}{ LDL-cholesterol, $\mathrm{mmol} / \mathrm{L}$} \\
\hline Crude & $3.20(0.06)$ & $3.32(0.04)$ & $3.24(0.04)$ & $3.09(0.06)^{\star \star}$ \\
\hline Adjusted & $3.21(0.06)$ & $3.29(0.04)$ & $3.20(0.04)$ & $3.24(0.06)$ \\
\hline \multicolumn{5}{|c|}{ Triglycerides, $\mathrm{mmol} / \mathrm{L}$} \\
\hline Crude & $1.43(0.06)$ & $1.14(0.03)^{*}$ & $1.28(0.04)^{\star, \star \star}$ & $1.16(0.05)^{\star}$ \\
\hline Adjusted & $1.38(0.06)$ & $1.16(0.03)^{\star}$ & $1.23(0.04)^{\star}$ & $1.22(0.05)^{\star}$ \\
\hline \multicolumn{5}{|c|}{$\mathrm{HbA}_{1 \mathrm{c}}, \mathrm{mmol} / \mathrm{L}$} \\
\hline Crude & $35.9(0.3)$ & $36.2(0.2)$ & $36.5(0.2)$ & $36.2(0.3)$ \\
\hline Adjusted & $36.5(0.3)$ & $35.9(0.2)$ & $36.4(0.2)^{\star *}$ & $36.6(0.3)^{\star \star}$ \\
\hline \multicolumn{5}{|l|}{ Albumin, $\mathrm{g} / \mathrm{L}$} \\
\hline Crude & $45.8(0.2)$ & $44.9(0.1)^{\star}$ & $45.4(0.1)^{\star \star}$ & $45.0(0.2)^{\star}$ \\
\hline Adjusted & $45.3(0.2)$ & $45.2(0.1)$ & $45.2(0.1)$ & $44.9(0.2)$ \\
\hline \multicolumn{5}{|c|}{ Alanine aminotransferase, $\mathrm{U} / \mathrm{L}$} \\
\hline Crude & $31.9(1.0)$ & $25.1(0.6)^{\star}$ & $29.0(0.7)^{\star, \star \star}$ & $24.4(1.0)^{\star, \star \star \star}$ \\
\hline Adjusted & $29.3(1.0)$ & $26.5(0.6)^{*}$ & $27.4(0.7)$ & $25.6(0.9)^{\star}$ \\
\hline \multicolumn{5}{|c|}{ Aspartate aminotransferase, $\mathrm{U} / \mathrm{L}$} \\
\hline Crude & $23.1(0.6)$ & $22.6(0.3)$ & $23.1(0.4)$ & $21.6(0.6)^{\star, \star \star \star \star}$ \\
\hline Adjusted & $23.1(0.6)$ & $22.6(0.3)$ & $22.8(0.4)$ & $22.1(0.6)$ \\
\hline \multicolumn{5}{|c|}{$\gamma$-Glutamyltranspeptidase, $\mathrm{U} / \mathrm{L}$} \\
\hline Crude & $30.5(1.8)$ & $24.0(1.0)^{\star}$ & $26.2(1.2)^{\star}$ & $20.7(1.7)^{\star, \star \star \star}$ \\
\hline Adjusted & $28.0(1.8)$ & $25.3(1.0)$ & $24.2(1.2)$ & $22.5(1.7)^{\star}$ \\
\hline \multicolumn{5}{|c|}{ Creatinine, $\mu \mathrm{mol} / \mathrm{L}$} \\
\hline Crude & $82.7(0.9)$ & $74.7(0.5)^{\star}$ & $80.5(0.6)^{\star, \star \star}$ & $72.7(0.9)^{\star, \star \star, \star \star \star}$ \\
\hline Adjusted & $77.5(0.8)$ & $77.1(0.4)$ & $77.4(0.5)$ & $76.5(0.7)$ \\
\hline \multicolumn{5}{|c|}{ Uric acid, mmol/L } \\
\hline Crude & $0.35(0.005)$ & $0.30(0.003)^{\star}$ & $0.33(0.003)^{\star, \star \star}$ & $0.28(0.005)^{\star, \star \star *, * \star \star \star}$ \\
\hline Adjusted & $0.32(0.004)$ & $0.31(0.002)^{*}$ & $0.31(0.003)^{*}$ & $0.29(0.004)^{*, * *, * \star \star \star}$ \\
\hline
\end{tabular}

the absolute ethanol consumption. The fact that liver enzyme levels were not very high in our population confirms that there were not many excessive drinkers.

Wine consumers had the lowest $\mathrm{HbA}_{1 \mathrm{c}}$-levels. It has been suggested that moderate alcohol consumption relates to a lower diabetes risk, partly as a result of increases in HDL-cholesterol. ${ }^{26}$ More specifically, a previous study in a female population showed that $25-30 \%$ of the reduced diabetes risk associated with moderate alcohol consumption can be explained by increased adiponectin concentrations. ${ }^{27}$ Another study showed that HDL-cholesterol explained $78 \%$ of the inverse relation between alcohol and diabetes. ${ }^{28}$ Moreover, a systematic review showed that moderate alcohol consumption may decrease $\mathrm{HbA}_{1 \mathrm{c}}$ concentrations. ${ }^{29}$ However, it is not clear whether intakes of wine, beer or spirits are equally associated with diabetes risk.

Besides the extending of our findings to previous scientific studies, there are several strengths and limitations of the current study that warrant attention. First of all, 
Table 5 Crude and adjusted individual pattern scores from principal component analysis on energy-adjusted food group intakes according to alcoholic beverage preference of 1653 participants from the NQplus study

\begin{tabular}{|c|c|c|c|c|}
\hline & \multicolumn{3}{|c|}{ Alcoholic beverage preference } & \multirow[b]{2}{*}{ Non-consumer } \\
\hline & Beer & Wine & Spirit/no preference & \\
\hline Per cent & 13 & 43 & 29 & 15 \\
\hline \multicolumn{5}{|c|}{ Factor 1 'Meat' } \\
\hline Crude & $0.20(0.07)$ & $-0.03(0.04)^{\star}$ & $0.08(0.05)^{\star, \star \star}$ & $-0.25(0.06)^{\star, \star \star, \star \star \star \star}$ \\
\hline Adjusted & $0.09(0.07)$ & $0.03(0.04)$ & $0.02(0.04)$ & $-0.22(0.06)^{\star, \star \star \star \star \star \star \star}$ \\
\hline \multicolumn{5}{|c|}{ Factor 2 'Snacks and drinks' } \\
\hline Crude & $0.20(0.07)$ & $-0.12(0.04)^{\star}$ & $0.02(0.05)^{\star, \star \star}$ & $0.13(0.06)^{\star, \star \star, \star \star \star \star}$ \\
\hline Adjusted & $0.01(0.06)$ & $-0.01(0.04)$ & $0.00(0.04)$ & $0.01(0.06)$ \\
\hline \multicolumn{5}{|c|}{ Factor 3 'Salads' } \\
\hline Crude & $-0.30(0.07)$ & $0.18(0.04)^{\star}$ & $-0.003(0.04)^{\star, \star \star}$ & $-0.24(0.06)^{\star, * \star \star, * \star \star}$ \\
\hline Adjusted & $-0.15(0.07)$ & $0.11(0.04)^{*}$ & $0.03(0.04)^{*}$ & $-0.23(0.06)^{\star \star, \star \star \star}$ \\
\hline \multicolumn{5}{|c|}{ Factor 4 'Bread' } \\
\hline Crude & $0.13(0.07)$ & $-0.04(0.04)^{*}$ & $-0.04(0.05)^{*}$ & $0.08(0.06)^{\star, \star \star * \star \star \star \star}$ \\
\hline Adjusted & $0.07(0.07)$ & $-0.01(0.04)$ & $-0.08(0.05)$ & $0.11(0.07)^{\star \star \star}$ \\
\hline \multicolumn{5}{|c|}{ Factor 5 'Potatoes and sweets' } \\
\hline Crude & $-0.18(0.07)$ & $-0.01(0.04)^{\star}$ & $0.13(0.05)^{\star, \star \star}$ & $-0.06(0.06)^{\star, \star \star *, \star \star \star}$ \\
\hline Adjusted & $-0.07(0.07)$ & $-0.07(0.04)$ & $0.16(0.05)^{\star, \star \star}$ & $-0.04(0.06)^{\star \star \star}$ \\
\hline \multicolumn{5}{|c|}{ Factor 6 'Low-fat dairy and cereals' } \\
\hline Crude & $-0.03(0.07)$ & $0.05(0.04)^{*}$ & $-0.10(0.05)^{\star, \star \star \star}$ & $0.07(0.06)^{\star, \star \star * *}$ \\
\hline Adjusted & $0.04(0.07)$ & $0.02(0.04)$ & $-0.07(0.05)$ & $0.05(0.07)$ \\
\hline
\end{tabular}

confounding factors were selected using DAGs or causal diagrams to ensure appropriate adjustment. DAGs are graphical models for causal relations that underlie a research question and are as such a useful way to summarise one's qualitative beliefs about the causal model. Adjustment for the covariates from the identified minimal sufficient adjustment set minimises bias, ${ }^{20}$ given that no large measurement error exists. However, it should be kept in mind that DAGs are qualitative, and do not give information about the strength and direction of the confounding. Furthermore, they require extensive knowledge about all pathways from exposure to outcome, which may not be fully known. Our DAG represented our belief about the causal model that the sociodemographic factors, such as age, gender, socioeconomic status, prevalent diseases, birth country, and religion, influence alcoholic beverage preference and other health behaviours. As it was the aim of the study to further uncover these pathways, we could not be completely certain about the causal model. Therefore, we have additionally adjusted the associations for other lifestyle factors, including smoking status and physical activity. However, additional adjustment for these other lifestyle factors did not substantially affect the associations under study, and hence confirmed our causal model. Nevertheless, residual confounding due to imperfectly measured may have occurred. For instance, we were unable to correct for all determinants of socioeconomic status, and used educational level and employment as a proxy. Furthermore, due to the cross-sectional design of the study, no causal relationship between the choice of alcoholic beverage and lifestyle habits and health could be confirmed. A second methodological factor that deserves some discussion is the use of a selfadministered FFQ to generate reliable and valid estimates of alcohol consumption that is known to be prone to measurement error. ${ }^{30}$ However, in the current study, alcohol consumers had higher levels of total and HDL-cholesterol compared to non-consumers. Given the known effects of alcohol on total and HDL-cholesterol, this strengthens our trust in the use of a FFQ to assess habitual alcohol consumption.

In conclusion, we hypothesised that alcoholic beverage preference may not be independently related to health status, but that it is merely a proxy for sociodemographic and lifestyle factors. In this homogeneous study population with appropriate adjustment for confounding factors, no large differences between the preference for beer, wine or other alcoholic beverages and dietary patterns were observed. However, some select differences according to alcoholic beverage preference were observed for cardiometabolic parameters, suggesting that wine consumers have a slightly more beneficial health status compared to beer consumers. Future prospective studies should investigate whether this is causally related to the choice of alcoholic beverage or whether this is an effect of residual confounding. 
Contributors EJMF designed the study and formulated the research question; DS carried out the study, analysed the data and drafted the manuscript. All authors critically revised the manuscript for important intellectual content and approved of the final version to be published.

Funding This research was supported by The European Foundation for Alcohol Research (ERAB) and The Dutch Beer Institute (grant number EA 11 45). The sponsors did not have any role in the design and conduct of the study; collection, management, analysis, and interpretation of the data; and preparation, review, or approval of the manuscript.

Competing interests None declared.

Ethics approval Medical ethical committee of Wageningen University.

Provenance and peer review Not commissioned; externally peer reviewed.

Data sharing statement No additional data are available.

Open Access This is an Open Access article distributed in accordance with the Creative Commons Attribution Non Commercial (CC BY-NC 4.0) license, which permits others to distribute, remix, adapt, build upon this work noncommercially, and license their derivative works on different terms, provided the original work is properly cited and the use is non-commercial. See: http:// creativecommons.org/licenses/by-nc/4.0/

\section{REFERENCES}

1. Ferrieres J. The French paradox: lessons for other countries. Heart 2004;90:107-11.

2. Gronbaek M, Deis $\mathrm{A}$, Sorensen $\mathrm{TI}$, et al. Mortality associated with moderate intakes of wine, beer, or spirits. BMJ 1995;310:1165-9.

3. Klatsky AL, Friedman GD, Armstrong MA, et al. Wine, liquor, beer, and mortality. Am J Epidemiol 2003;158:585-95.

4. Truelsen T, Gronbaek M, Schnohr P, et al. Intake of beer, wine, and spirits and risk of stroke: the Copenhagen city heart study. Stroke 1998;29:2467-72.

5. Alcácera MA, Marques-Lopes I, Fajó-Pascual M, et al. Alcoholic beverage preference and dietary pattern in Spanish university graduates: the SUN cohort study. Eur J Clin Nutr 2008;62:1178-86.

6. Barefoot JC, Grønbaek M, Feaganes JR, et al. Alcoholic beverage preference, diet, and health habits in the UNC Alumni Heart Study. Am J Clin Nutr 2002;76:466-72.

7. Tjønneland A, Grønbaek M, Stripp C, et al. Wine intake and diet in a random sample of 48763 Danish men and women. Am J Clin Nutr 1999;69:49-54.

8. Valencia-Martin JL, Galan I, Rodriguez-Artalejo F. The association between alcohol consumption patterns and adherence to food consumption guidelines. Alcohol Clin Exp Res 2011;35:2075-81.

9. Sluik D, Bezemer R, Sierksma A, et al. Alcoholic beverage preference and dietary habits: a systematic literature review. Crit Rev Food Sci Nutr 2015;12:0.

10. Feunekes GI, Van Staveren WA, De Vries JH, et al. Relative and biomarker-based validity of a food-frequency questionnaire estimating intake of fats and cholesterol. Am J Clin Nutr 1993;58:489-96.

11. Siebelink E, Geelen A, de Vries JH. Self-reported energy intake by FFQ compared with actual energy intake to maintain body weight in 516 adults. Br J Nutr 2011;106:274-81.
12. NEVO-tabel. Dutch Food Composition Table 2011/version 3. Bilthoven: RIVM, 2011.

13. Sluik D, van Lee L, Geelen A, et al. Alcoholic beverage preference and diet in a representative Dutch population: the Dutch national food consumption survey 2007-2010. Eur J Clin Nutr 2014;68:287-94.

14. The Dutch Beer Institute. "De Glazenstandaard" (standard serving sizes beer, wine, and spirits). http://www.kennisinstituutbier.nl/ glazenstandaard. (accessed 24 Aug 2015).

15. Willett WC, Howe GR, Kushi LH. Adjustment for total energy intake in epidemiologic studies. Am J Clin Nutr 1997;65(4 Suppl):1220S-8S. doi:discussion 1229S-1231S.

16. Savva SC, Lamnisos D, Kafatos AG. Predicting cardiometabolic risk waist-to-height ratio or BMI. A meta-analysis. Diabetes Metab Syndr Obes 2013;6:403-19.

17. Friedewald WT, Levy RI, Fredrickson DS. Estimation of the concentration of low-density lipoprotein cholesterol in plasma without use of the preparative ultracentrifuge. Clin Chem 1972;18:499-502.

18. Doumas BT, Peters T Jr. Serum and urine albumin: a progress report on their measurement and clinical significance. Clin Chim Acta 1997;258:3-20.

19. Sterne JA, White IR, Carlin JB, et al. Multiple imputation for missing data in epidemiological and clinical research: potential and pitfalls. BMJ 2009;338:b2393.

20. Greenland S, Pearl J, Robins JM. Causal diagrams for epidemiologic research. Epidemiology 1999;10:37-48.

21. Chiva-Blanch G, Arranz S, Lamuela-Raventos RM, et al. Effects of wine, alcohol and polyphenols on cardiovascular disease risk factors: evidences from human studies. Alcohol Alcohol 2013;48:270-7.

22. Bobak M, Skodova Z, Marmot M. Beer and obesity: a cross-sectional study. Eur J Clin Nutr 2003;57:1250-3.

23. Schütze $M$, Schulz $M$, Steffen $A$, et al. Beer consumption and the 'beer belly': scientific basis or common belief? Eur J Clin Nutr 2009:63:1143-9.

24. Bendsen NT, Christensen R, Bartels EM, et al. Is beer consumption related to measures of abdominal and general obesity? A systematic review and meta-analysis. Nutr Rev 2013;71:67-87.

25. Lemieux I, Pascot A, Couillard C, et al. Hypertriglyceridemic waist: a marker of the atherogenic metabolic triad (hyperinsulinemia; hyperapolipoprotein B; small, dense LDL) in men? Circulation 2000;102:179-84.

26. Rimm EB, Williams $\mathrm{P}$, Fosher $\mathrm{K}$, et al. Moderate alcohol intake and lower risk of coronary heart disease: meta-analysis of effects on lipids and haemostatic factors. BMJ 1999;319:1523-8.

27. Beulens JW, Rimm EB, Hu FB, et al. Alcohol consumption, mediating biomarkers, and risk of type 2 diabetes among middle-aged women. Diabetes Care 2008;31:2050-5

28. Beulens JW, van der Schouw YT, Moons KG, et al. Estimating the mediating effect of different biomarkers on the relation of alcohol consumption with the risk of type 2 diabetes. Ann Epidemiol 2013;23:193-7.

29. Schrieks IC, Heil AL, Hendriks HF, et al. The effect of alcohol consumption on insulin sensitivity and glycemic status: a systematic review and meta-analysis of intervention studies. Diabetes Care 2015;38:723-32.

30. Satija A, Yu E, Willett WC, et al. Understanding nutritional epidemiology and its role in policy. Adv Nutr 2015;6:5-18. 